\section{THE NEW RHINOCEROS}

THE acquisition of a living Rhinoceros belonging to a species hitherto unknown to science, is certainly a remarkable event, and one that may well give comfort to those who may have supposed that the field of zoological discovery is worked out. If so large a beast has hitherio escaped the observation of naturalists, how many smaller animals must there still remain for the zoological explorer. But the truth is that we know less about some of these very bulky animals than those of more moderate dimensions, as their very size renders the collection and preparation of specimens of them more difficult. The importation of such monsters in a living state is a still more serious undertaking, and it is only within the last few years that the Zoological Gardens of Europe have become wealthy and enterprising enough to find funds for such expensive luxuries.
The animal of which we are now speaking, was originally captured near Chittagong, at the northernmost extremity of the Bay of Bengal, in January 1868 , by some officers engaged in the supply of elephants for the Indian army. Some natives came into the station, and reported that a rhinoceros had fallen into a quicksand, at a place about sixteen hours' journey to the south, and had been unable to extricate itself. They had pulled it out by ropes attached to its neck, and had bound it between two trees, but were fearful of its breaking loose. Captain Hood and Mr. H. W. Wickes accordingly started with eight elephants, and brought the rhinoceros into Chittagong, where she was kept in a stockaded enclosure, "having a good bath excavated in the ground, and a comfortable shed attached to it." Here "Begum," as she was named, remained for nearly four years. Various negociations were entered into between the Zoological Society of London and the capturers, for her

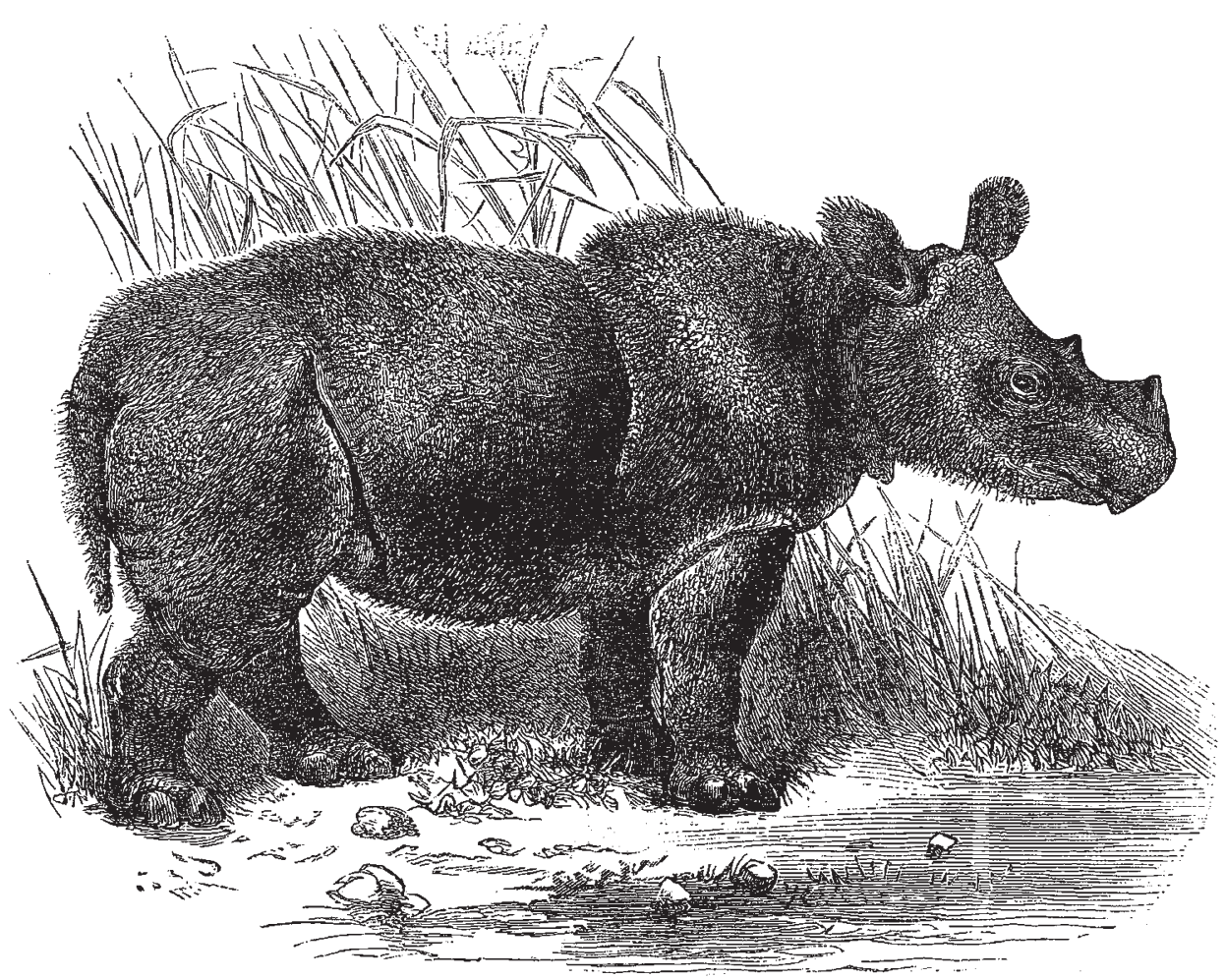

F1G. J.-Sumatran Rhinoceros

removal to this country, but these never came to any definite result. Besides the difficulty of arranging terms at such a distance apart, there seemed to be some question about the true ownership of the animal, which created additional embarrassment in the transaction. At length in the autumn of $187 \mathrm{I}, \mathrm{Mr}$. William Jamrach, the well-known dealer in living animals, being personally in Calcutta, was able to conduct the negociations to a successful result, and on his return to England, in February last, brought the animal with him. Upon her arrival "Begum" was immediately purchased by the Zoological Society, to whom, it was understood, the first offer was to be made, for the sum of $1,250 l$.

During the transit through Calcutta, this rhinoceros was examined by Dr. John Anderson, the Curator of the Indian Museum in that city. Dr. Anderson, thinking it possible that the animal might not live to reach England, had some figures of it made by a native artist, and drew up some notes on its external characters, which he communicated to the Zoological Society of London. In these notes, which have been published by the Zoological Society in their Proceedings (P. Z. S., 1872, p. 129), Dr. Anderson supposes the animal to be a Sumatran Rhinoceros (Rhinoceros sumatrensis of Cuvier), but comments upon several points in which it seemed to differ from former descriptions of that species, and upon its occurrence so far north of the hitherto known range of that species. When the rhinoceros arrived in London it was likewise referred to Rhinoceros sumatrensis-that being the only known Asiatic species of Rhinoceros with two horns, and was entered under this name in the Zoological Society's register of accessions, and is so spoken of in the new edition of the "Garden Guide." It is likewise mentioned and figured under this name in an article on Rhinoceroses, published in this journal for the 28 th of March last. The cut there given is 
now reproduced (see Fig. 2), in order to give an opportunity of comparing it with the figure (Fig. 1) of the true $R$. sumatrensis.

In July last Mr. William Jamrach received a female two-horned rhinoceros from Singapore, which is said to have been captured in a pitfall near Malacca, and placed it on deposit in the Zoological Society's Gardens. On comparing it with the female previously received from Chittagong, it became at once apparent that the two animals belonged to distinct, though nearly allied, species. The Malaccan animal, although undoubtedly adult, is much smaller-nearly as much as one thirdthan that from Chittagong. The fringe of long hairs on the posterior rim of the naked ears, which is very conspicuous in the Chittagong animal, is not present in the Malaccan example, in which, however, the whole interior of the ears is filled with short hairs. The whole body of the Malaccan animal is covered with coarse granulations, which are hardly apparent in that from Chittagong. The tail of the Malaccan animal is shorter and nearly naked; in that from Chittagong it is longer and tufted at the extremity. The head of the former animal is much narrower than that of the latter, as is particularly apparent when the distance between the ears of each is examined from a front view, and there can be no doubt that the skulls of the two animals, whenever they can be compared, will exhibit marked differences in size and structure.

Under these circumstances the Council of the Zoological Society thought it would be advisable to add the second animal also to their living collection, and accordingly agreed to purchase it of Mr. Jamrach for the sum of $600 l$. Unfortunately it did not live long in the Society's gardens.

Upon reference to authorities upon the Sumatran Rhinoceros, which was first described by $\mathrm{Mr}$. William Bell in the Philosophical Transactions of the Royal Society for 1793, and afterwards by Sir. Stamford Raffles in this country and by Cuvier and other writers in France, it became evident that the Malaccan animal was the true $R$ hinoceros sumatrensis of authors. This would be presumably the case, because the Fauna of the Britsh settlement of Malacca is nearly identical with that of the adjacent island of Sumatra. The Chittagong animal, its northern representative, is therefore proposed to be called the Hairy-eared Rhinoceros (Rhinoceros lasiotis), from its peculiar ear-fringe of long hairs, which has been already spoken of. How far the Sumatran Rhinoceros extends north along the Malayan peninsula is not yet as-

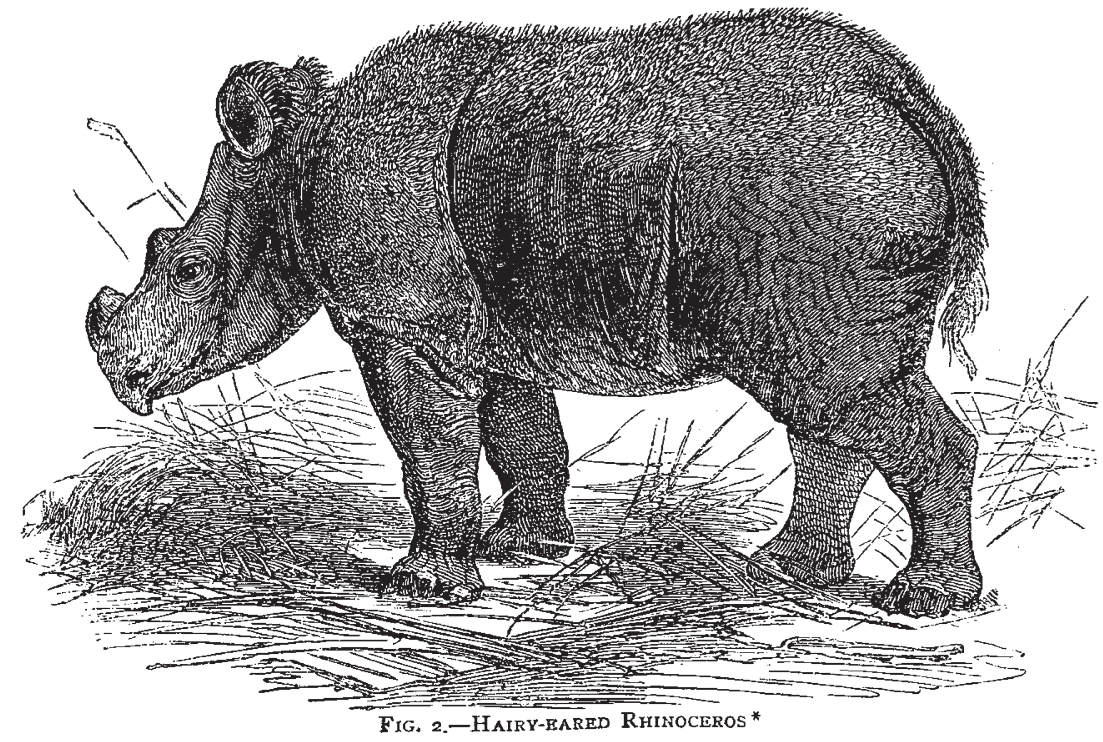

certained, because, although Two-horned Rhinoceroses are known to occur in several intermediate localities, it is uncertain to which of the two allied species they belong. The range of $R$. lasiotis is likewise quite a matter of uncertainty at present, the animal being utterly unknown except from the individual in the Zoological Society's Gardens. But it is probable that it extends into Assam, where there are reports of the occurrence of a Two-horned species of Rhinoceros.

Besides the two Rhinoceroses just spoken of, two other specimens of Asiatic Two-horned Rhinoceroses have been imported alive into Europe since the commencement of the present year. One of these was purchased by an agent of one of the American travelling menageries, and exported to New York; the other is now in the gardens of the Zoological Society of Hamburgh. Both these animals are said to have been received from Singapore, and to resemble exactly the Malaccan animal in London. of the second a figure and description have been published in a Hamburgh journal (Der Reform); which shows that the animal is certainly the true $R$. sumatrensis.

* It should be stated that this figure is drawn on a smaller scale than that of the Sumatran Rhinoceros, the latter being really the smaller animal. - ED.
By the addition of these two animals to their Menagerie the Zoological Society have now been able to exhibit side by side specimens of four (out of the six certainly known) living species of Rhinoceros-a wonderful advance, when we consider that a very few years ago the Indian $R$ hinoceros unicornis was alone known in Europe in a living state. The two species remaining to be obtained are the Javan Rhinoceros (Rhinoceros sondaicus), a smaller representative of the One-horned Indian, and the White Rhinoceros of Africa (Rhinoceros simus). It need hardly be added that any correspondents of NATURE who may be able to assist in supplying these desiderata will not only be conferring a benefit on science, but will be liberally dealt with by the Council of the Society.

\section{RECENT FALLS OF METEORITES IN FRANCE} AND ITALY

THE French Academy of Sciences has recently received several important and interesting accounts of the fall of two or three meteoric masses in France and Italy. On the 23 rd of July, about half-past five on a still afternoon, with a perfectly clear sky and a bright sun, a 